\title{
LUT
}

University

\section{Measurement Accuracy Requirements for the Efficiency Classification of Converters and Motors}

Aarniovuori Lassi, Kärkkäinen Hannu, Niemelä Markku, Pyrhönen Juha

This is a Author's accepted manuscript (AAM) version of a publication

published by IEEE

in 21st European Conference on Power Electronics and Applications (EPE'19 ECCE Europe)

DOI: $\quad 10.23919 /$ EPE.2019.8915560

Copyright of the original publication: (C) 2019 IEEE

Please cite the publication as follows:

Aarniovuori, L., Kärkkäinen, H., Niemelä, M., Pyrhönen, J. (2019). Measurement Accuracy

Requirements for the Efficiency Classification of Converters and Motors. 21st European

Conference on Power Electronics and Applications (EPE'19 ECCE Europe). DOI: 10.23919/

EPE.2019.8915560

This is a parallel published version of an original publication.

This version can differ from the original published article. 


\title{
Measurement Accuracy Requirements for the Efficiency Classification of Converters and Motors
}

\author{
Lassi Aarniovuori ${ }^{1}$, Hannu Kärkkäinen², Markku Niemelä², Juha Pyrhönen² \\ ${ }^{1}$ Aston University / EAS \\ ${ }^{2}$ LUT-University \\ Aston Triangle, B4 7ET \\ P.O. Box 20, FI-53851 \\ Birmingham, U.K. \\ Lappeenranta, Finland \\ E-Mail: 1.aarniovuori@aston.ac.uk \\ URL: http://www.aston.ac.uk \\ hannu.s.karkkainen@lut.fi \\ URL: http://www.lut.fi
}

\section{Keywords}

Efficiency, Measurement, AC machine, Voltage Source Converter, Electrical drive, Standardization.

\begin{abstract}
Electrical machines play a major role in the electrical energy consumption in the modern world; therefore, the efficiency of electrical machines has been regulated for a long time by different authorities. Recently, the international efficiency classes for converters and converter-fed machine packages were introduced by IEC. The increased efficiency of the devices creates a challenge for accurate loss and efficiency determination of these devices. This paper examines the measurement accuracy of the directon-line and converter-fed electrical machines, frequency converters, and converter-fed machine packages from a theoretical basis. The measurement uncertainty is presented as a function of the rated powers of the devices and as a function of the efficiency classes.
\end{abstract}

\section{Introduction}

Commonly used methods for the loss and efficiency determination of the converters are calculationbased methods. The parameters of the components are used together with theoretical equations. Two other important means of defining the losses and the efficiency are the method based on input and output power measurement, and the calorimetric method. For the electrical machines also the finite element analysis (FEM) in 2D or 3D and indirect efficiency determination are used. The indirect determination of the efficiency of an electric machine using segregation of losses method has been studied extensively in the literature by different authors [1]-[5]. The indirect method is intended only for induction machines, but it has been considered also for permanent magnet synchronous machines [6],[7]. Calorimeters have been constructed and used to obtain the losses of the converters and electrical machines, but they have not become popular and the problems that are typically associated with them are the complexity of the system and a rather long measurement time [8]. Three different methods; input-output, calorimetric, and calculation are used in [9] to obtain the losses of a voltage source converter while in [10] a workflow starting from measurement instruments' data sheet information to final measurement uncertainty result is presented for three different frequency converters with different power ratings.

\section{Uncertainty in Electric Motor Systems' Efficiency Measurements}

The efficiency or loss determination method that is based on input and output power measurements is widely used in all kinds of applications due to its simplicity. The measured input power $P_{\text {in }}$ and output power $P_{\text {out }}$ are used to determine the efficiency as a fraction $P_{\text {in }} / P_{\text {out }}$. The total machine losses $P_{\text {loss }}$ are now the difference between the mechanical and electrical power

$$
P_{\text {loss }}=P_{\text {in }}-P_{\text {out }}
$$


However, when the device under test is a high efficiency device, this method suffers from inaccuracy, since a small difference of two relatively large power values is caused by losses. The uncertainty in losses can be obtained by combining the input and output power measurement uncertainties using the square root of the sum of squares method by assuming that the uncertainties of the powers do not correlate. In this case, the uncertainty in losses is

$$
U\left(P_{\text {loss }}\right)=\sqrt{U\left(P_{\text {in }}\right)^{2}+U\left(P_{\text {out }}\right)^{2}},
$$

where $U\left(P_{\text {in }}\right)$ and $U\left(P_{\text {out }}\right)$ are the uncertainties of the input and output powers. In the following analysis, it is assumed that the uncertainties of both powers are equal and the loss uncertainty equation can be simplified to

$$
U\left(P_{\text {loss }}\right)=\sqrt{2} U(P)
$$

where $U(P)=U\left(P_{\text {in }}\right)=U\left(P_{\text {out }}\right)$. The efficiency and input and output powers have the following relationships

$$
\eta=\frac{P_{\text {out }}}{P_{\text {in }}} \leftrightarrow P_{\text {in }}=\frac{P_{\text {out }}}{\eta} \leftrightarrow P_{\text {out }}=\eta P_{\text {in }} .
$$

Substituting $P_{\text {in }}$ from the second form of (4) to (1), we get

$$
P_{\text {loss }}=\frac{P_{\text {out }}}{\eta}-P_{\text {out }}=\left(\frac{1-\eta}{\eta}\right) P_{\text {out }} .
$$

To obtain the relative loss uncertainty by dividing (3) with the losses (5)

$$
U\left(P_{\text {loss }}\right)_{\text {rel }}=\sqrt{2} \frac{\eta}{1-\eta} \frac{U(P)}{P_{\text {out }}}=\sqrt{2} \frac{\eta}{1-\eta} U(P)_{\text {rel }}
$$

which shows that the relative loss uncertainty $U\left(P_{\text {loss }}\right)_{\text {rel }}$ is approaching infinity when the efficiency is approaching unity with all input and output power uncertainties

$$
\lim _{\eta \rightarrow 1} U\left(P_{\text {loss }}\right)_{\text {rel }}=\infty .
$$

Equation (6) can be used to obtain the required uncertainty limit for the input and output power uncertainty to obtain the specific loss uncertainty when the efficiency of the device is known

$$
U(P)_{\mathrm{rel}}=\sqrt{2} \frac{1-\eta}{\eta} U\left(P_{\text {loss }}\right)_{\mathrm{rel}} .
$$

It should be noted that the relative uncertainty $U\left(P_{\text {loss }}\right)_{\text {rel }}$ here is the total uncertainty of the input and output powers (electrical or mechanical) and it includes both type A uncertainty and type B uncertainty [11]. Type A uncertainty is related to the repetition of measurements and describes how much the average of this set of repetitions can fluctuate. Type B uncertainty is associated with the measurement instruments and their specifications.

\section{Direct-on-line machines}

The efficiency limits of the different international efficiency classes for the electrical machines with direct-on-line starting capability are given in [12] and presented in Figure 1 for four-pole machines. The standard covers the rated powers from $0.12 \mathrm{~kW}$ to $1000 \mathrm{~kW}$ and all electrical machine technologies if they are rated for direct-on-line operation. The standard covers the machines that have one to four pole pairs and are capable of operating continuously with the rated power not exceeding the specific limit set by the temperature rise of windings. The covered rated voltage range in the standard is $50 \mathrm{~V}$ to $1 \mathrm{kV}$, the ambient temperature range from $-20^{\circ} \mathrm{C}$ to $+60^{\circ} \mathrm{C}$ and the operational altitude up to 4000 meters above sea level. Typical machine technologies that fit under the coverage of this standard are induction machines, line start permanent magnet synchronous machines and direct-on-line synchronous reluctance machines. The allowed measurement uncertainty for input and output power to obtain a loss uncertainty of 5\% is given in Figure 1 as calculated using (8). The 5\% loss tolerance is expected to be an acceptable error in the losses. 
For the sake of clarity, a numerical example is given here for two machines with two different ratings. The corresponding efficiency values and related measurement uncertainties have been also marked in Figure 1. The first machine is a $7.5 \mathrm{~kW}$ IE3-rated machine with efficiency of $90.4 \%$ marked with ' $x$ ' in the figure. It can be read from the plot that the input and output power measurement uncertainties have to be around $0.4 \%$ to obtain the loss tolerance of $5 \%$. The input power of the machine is $7.5 \mathrm{~kW} / 0.904$ $=8.3 \mathrm{~kW}$ and the losses are $800 \mathrm{~W}$. The output power uncertainty $0.4 \%$ of $7.5 \mathrm{~kW}$ gives $30 \mathrm{~W}$ and $0.4 \%$ of $8.3 \mathrm{~kW}$ is $33 \mathrm{~W}$. Combining the uncertainties using (2) gives $45 \mathrm{~W}$ that is around $5 \%$ of the losses. Similarly, for a $500 \mathrm{~kW}$ IE1-rated machine marked with ' $O$ ' in the figure with efficiency of $94 \%$ we get $0.2 \%$ uncertainty that is $1000 \mathrm{~W}$ for the output power and $1064 \mathrm{~W}$ for the input power that results is combined uncertainty of $1460 \mathrm{~W}$. This is around $5 \%$ of the $30 \mathrm{~kW}$ losses.

It can be seen in Figure 1 that the losses of the motors can be obtained with 5\% loss tolerance up to rated powers of $0.55 \mathrm{~kW}$ when the input and output power measurement uncertainties are below $0.5 \%$. Similarly, when the measurement uncertainty of the input and output power is below $0.2 \%$, all the motors up to rated power of $11 \mathrm{~kW}$ can be measured with this loss tolerance. If the total measurement uncertainty of the input and output power is below $0.09 \%$, the losses of all motors up to rated power of $1000 \mathrm{~kW}$ can be determined with this reasonable 5\% loss tolerance. The figure shows the fact that the power measurement accuracy requirement is a function of the rated power in case of motors. In practice, the efficiency of a large high efficiency machine is the most troublesome to be determined accurately.

The difference in the efficiency class limits of the direct-on-line motors are around $15 \%$ in losses i.e. the IE3 limit is $15 \%$ less losses than the IE2 limit. The difference in the losses of the efficiency classes is sometimes used also to give insight how accurately the losses should be measured, but according to the standard IEC 60034-1 [13] these limits do not include measurement uncertainty. More precisely IEC 60034-1 says:"Tolerance is the maximum allowed deviation between the test result of a quantity from table 20 and the declared value on the rating plate or in the catalogue. As long as test procedures and test equipment according to IEC standards are used, the test result shall not exceed the allowed deviation independent of test laboratory or equipment. Tolerance does not cover the uncertainty of a test procedure, i.e. the deviation between the test result and the true value." Table 20 mentioned in the

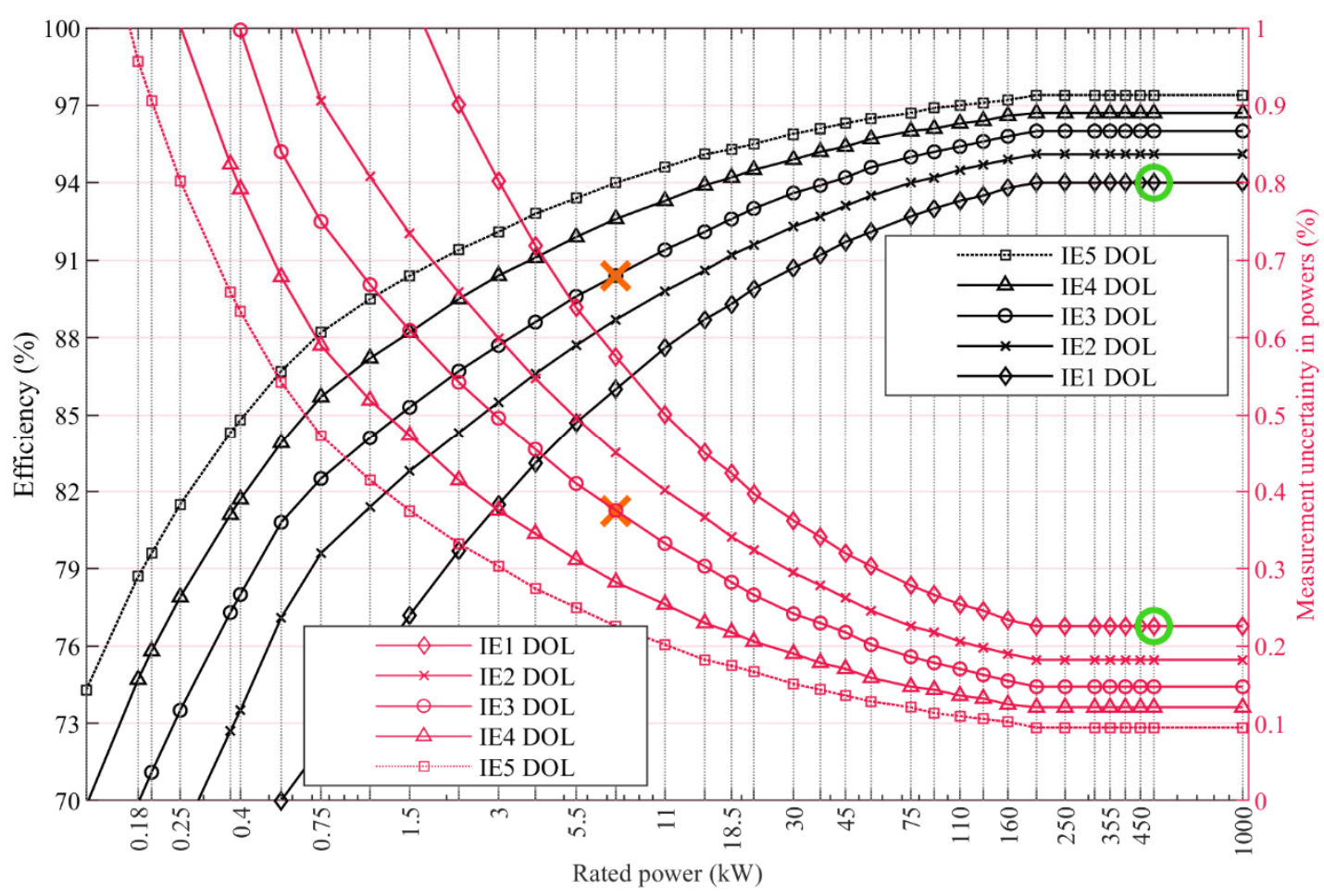

Figure 1. The IEC efficiency limits for direct-on-line motors according IEC 60034-30-1 (left axis) and the input and output power measurement uncertainty required to obtain 5\% loss tolerance (right axis) as a function of the rated power of the motor. The power measurement uncertainty is assumed equal for input and output power. The 'IE5' is presented as a dotted line, since it is not an official efficiency class for DOL machines. 
quotation lists all relevant quantities considering an electrical machine and their tolerances. For efficiency, the tolerance is defined as $-15 \%$ of the total losses. So, in fact the measurement uncertainty is an extra uncertainty in the efficiency value. This means that with $5 \%$ loss uncertainty that originates from the measurement procedure itself, the losses related to the given efficiency value are within $20 \%$ of the true losses. For example, consider a motor with $90 \%$ rated efficiency: the measured efficiency result must be at least $88.5 \%$ (losses are $10 \%$ of the input power, and $15 \%$ of $10 \%$ is $1.5 \%$ ) when measured according to the standard methods with equipment fulfilling the requirement of the standard. Now, if the efficiency measurement result is exactly $88.5 \%$ and the uncertainty of the result is $5 \%$ of the losses, the true efficiency can in fact be anywhere between $87.9 \%$ and $89.1 \%$ but based on the measurement result, the motor would fulfill the requirements of the standard and could be classified according to $90 \%$ efficiency.

\section{Converter-fed machines}

The efficiency limits for the converter-fed machines are given in IEC 60034-30-2 [14]. The IEC efficiency limits for converter-fed machines are given for different rated rotational speed ranges instead of pole pair numbers that are used for DOL-machines. The efficiency limits for converter fed machines are adjusted by an allowance recognizing the converter-caused additional harmonic losses and by using partial speed $(90 \%)$ in the measurement

$$
\eta_{\mathrm{n}}=\frac{1}{1+\left(1+r_{\mathrm{HL}}\right)\left(\frac{1}{\eta_{\mathrm{ref}}}-1\right)},
$$

where $r_{\mathrm{HL}}$ is the additional harmonic loss factor that is $0.15(15 \%)$ for machines with rated power up to and including $90 \mathrm{~kW}$ and $0.25(25 \%)$ for machines with rated powers higher than $90 \mathrm{~kW} . n_{\text {ref }}$ is the corresponding reference efficiency limit table value that is equal to DOL efficiency limit for IE1 to IE4 classes. The IE5 limits are used at the moment only to determine the IE5 efficiency class for converter fed machines.

The efficiency class limits and the allowed measurement uncertainty for input and output power to

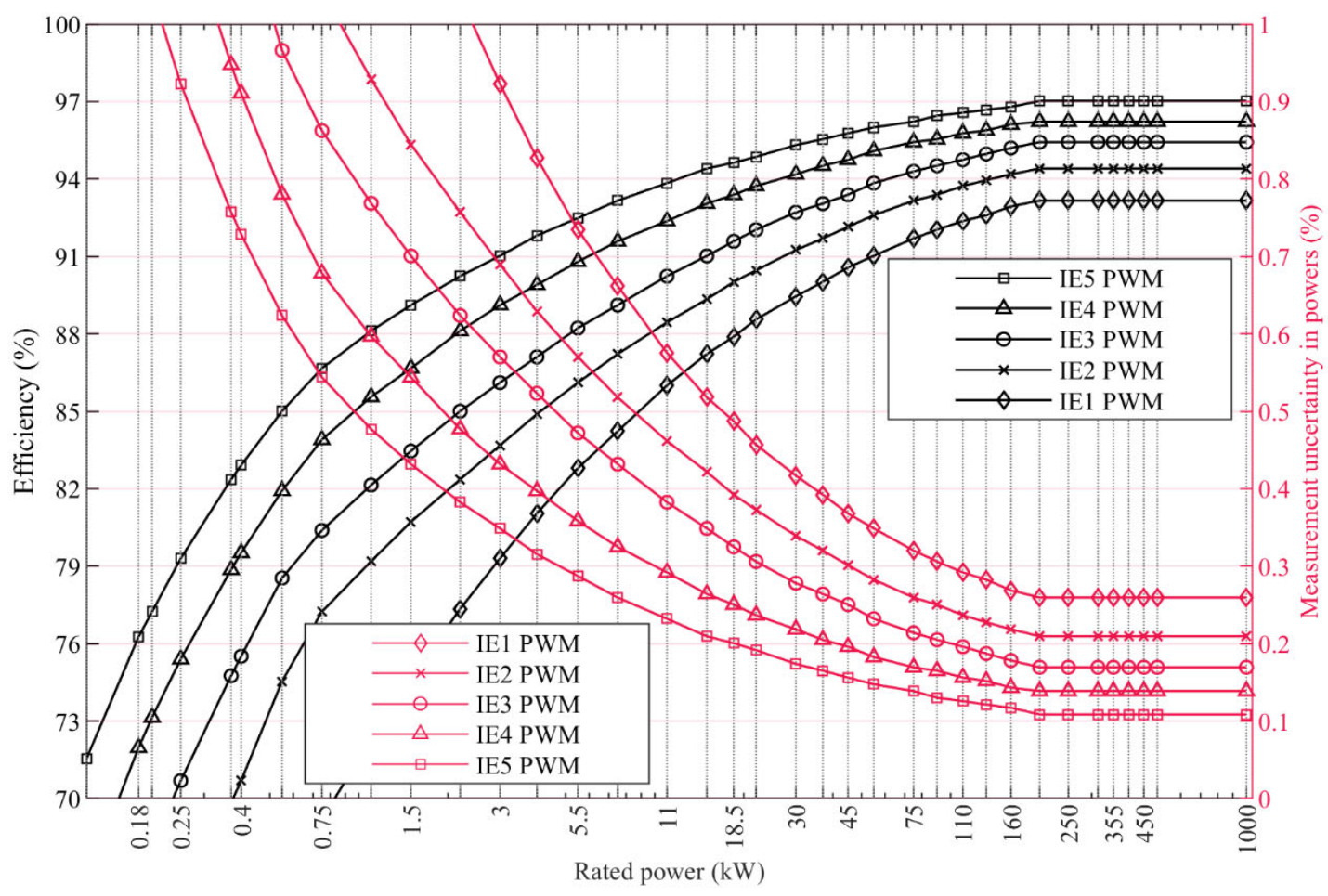

Figure. 2. The efficiency limits for the frequency converter driven electric machines with the rated speeds of $1200 \ldots 1800 \mathrm{rpm}$ according to IEC 60034-30-2 (left axis) and the input and output power measurement uncertainty required to obtain 5\% loss tolerance (right axis) as a function of the rated power of the motor. The power measurement uncertainty is assumed equal for input and output powers 
obtain a loss uncertainty of $5 \%$ is given in Figure 2. for the different IE-classes of converted-fed machines. When comparing Figures 1 and 2, it can be observed that the efficiency to obtain a specific IE-class is higher for DOL-machines and consequently the measurement accuracy requirement is lower for the efficiency class in question for the converter-fed machines. To obtain the losses of the converterfed machines up to IE5 efficiency class with the loss tolerance of 5\%, below $0.11 \%$ input and output power measurement uncertainty is required.

\section{Frequency converters}

The frequency converter international efficiency classes are given in IEC 61800-9-2 [15] as a respect of reference loss class instead of efficiencies that are used for the electrical machines. The standard uses the term complete drive module (CDM) to describe all the electronic equipment that are used to control electrical machines. The standard introduces IE0, IE1 and IE2 -classes for a CDM. The IE1 is the reference class and if the device losses are $25 \%$ higher than the reference losses given in the standard, the rating of the device is IE0 and if they are $25 \%$ lower, the rating is IE2. The reference losses as well as the loss bands to obtain IE0 or IE2 classes are given in Figure 3 a) while Figure $3 \mathrm{~b}$ ) is used to show the related losses as efficiencies.

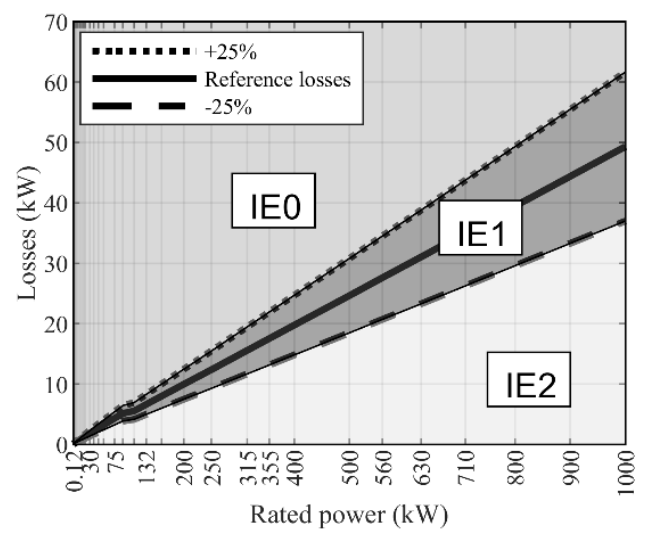

a ) Reference losses

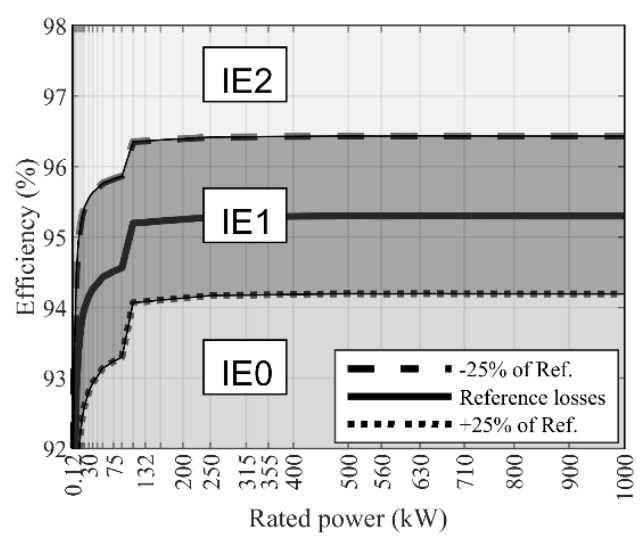

b) Efficiencies

Figure 3. The reference losses for the frequency converters according to IEC 61800-9-2 (a) and reference losses presented as efficiency curves (b) as a function of the rated power.

The values of the converter efficiencies in Figure 3 b) are relatively low. The values in Figure 3 are reference values and the measurement uncertainty is added on top of the determined losses before the value is used for the efficiency classification. Similarly, as in the case of machines, we can estimate the input and output measurement uncertainty to obtain the loss uncertainty of $5 \%$ that is shown in Figure 4 a). Figure 4 b) shows the measurement uncertainties for IE2-rated converters to obtain a loss tolerance from $5 \%$ down to $1 \%$.

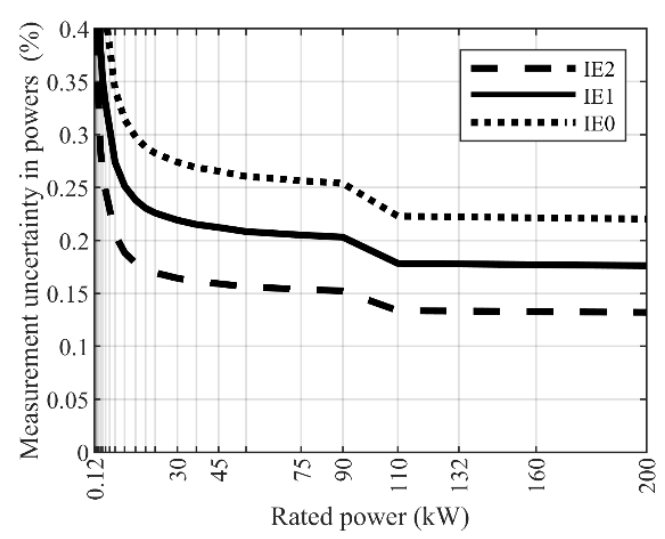

a ) Measurement uncertainty

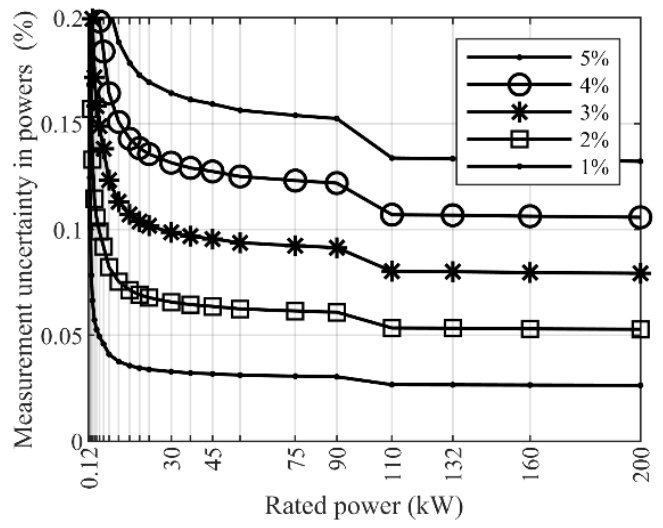

b ) The different loss uncertainties

Figure. 4. Measurement uncertainties of the input and output power to obtain the $5 \%$ loss uncertainty for IE0...IE2 rated converters (a) and the measurement uncertainties for IE2-rated converter to obtain the loss tolerances from 5\% down to $1 \%$ (b). 
Generally, the measurement uncertainty in the input and output power to obtain 5\% loss tolerance is at the same level as in the case of motors. The converter efficiencies do not strongly depend on the rated power, which is the case with motors. Therefore, the minimum measurement uncertainty requirement for a converter is relatively constant, but already quite strict at low power levels because of the high efficiency of these devices. To obtain a lower loss uncertainty than $5 \%$ is challenging as given in Figure $4 \mathrm{~b}$ ), since the measurement uncertainties in Figures $1 \ldots 3$ are total measurement uncertainties that includes the type A uncertainty and type B uncertainty. However, with data processing and stateof-the-art devices these kind of total measurement uncertainties are achievable.

\section{Converter-machine packages}

The converter-machine packages are denoted as power drive systems (PDSs) in [15]. Similarly, as for the frequency converters, the IES classes are given as reference losses. The reference losses of the PDSs are given in Figure 5 a). Since the total efficiency of the converter-machine package is lower than the single device efficiency, also the related efficiencies of the reference loss classes are lower for PDSs (Figure $5 \mathrm{~b}$ ) than for CDMs.

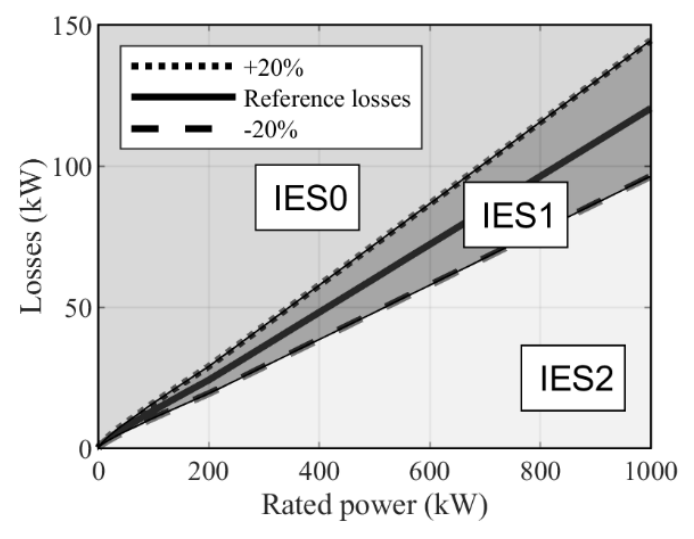

a )

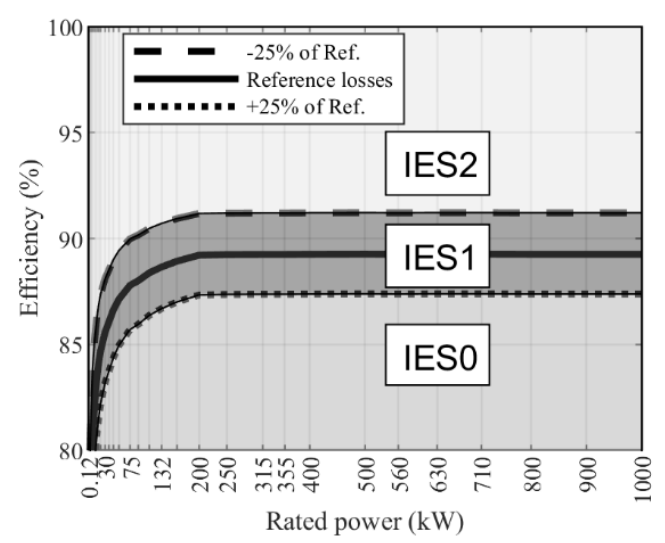

b )

Figure 5. a) Reference losses for the frequency converters as a function of the rated power. b) Reference losses presented as efficiency curves.

The allowed measurement uncertainty for input and output power to obtain a loss uncertainty of $5 \%$ is given in Figure 6 for the PDSs' efficiency classes IES0-IES2.

The curves in Figure 6 show that it is much easier to measure the losses of a power drive system with low uncertainty than the losses of a converter or a motor. Since the system efficiency is lower, also the requirements for the measurement instruments' specifications can be looser for PDSs than for motors or converter. In fact, when using the square root of the sum of squares method to propagate the uncertainties, it would be reasonable to use 7\% for PDSs that is the result of combining the converter and motor 5\% loss uncertainties. However, even a 5\% loss tolerance is relatively broad for PDSs, when the same instruments that are used in the converters' and motors' classifications are used.

\section{The Accuracies of the measurement instruments given in the standards}

The standards provide the specifications for the minimum accuracies for the measurement instruments that are used in the efficiency classification [15], [16]. In [15] it is given that the uncertainty specified by the instrument manufacturer of the power meters used in frequency converter and drive system measurements shall be $0.2 \%$ of the rated apparent output power or better for the total active power at $50 \mathrm{~Hz} / 60 \mathrm{~Hz}$. This is the total uncertainty of the power meter including possible sensors. The bandwidth of power meters and sensors shall be sufficiently wide to ensure an error of the total active power of less or equal to $0.3 \%$ of the rated apparent output power. The assumption made in the previous analysis was that the uncertainty is evenly distributed between the input and output power, which is very well valid for the frequency converters. The passive rectifier bridge in the input side of the converter distorts the 


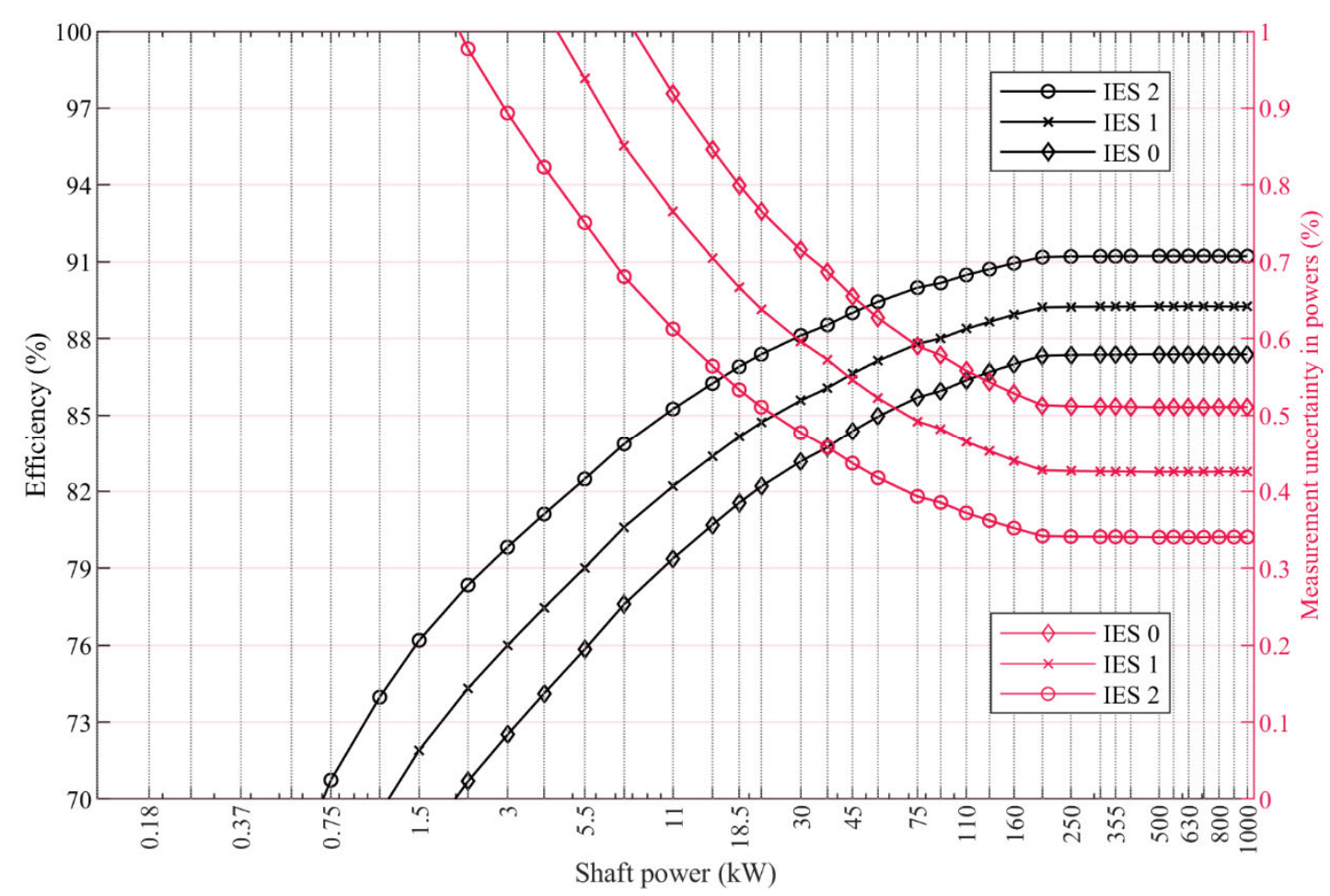

Figure. 6. Efficiency limits for power drive systems according to IEC 61800-9-2 (left axis) and the input and output power measurement uncertainty required to obtain $5 \%$ loss tolerance (right axis) as a function of the mechanical output power. The power measurement uncertainty is assumed equal for the input and output power.

current waveform while at the output side the voltage is distorted because of PWM. The $0.2 \%$ accuracy can be expected to give below $5 \%$ loss uncertainty for IE0 and IE1 rated converters and slightly over $5 \%$ for the IE2-rated converters that can be seen from Figure $4 \mathrm{a}$. The accuracy seems to be well justified and it is reachable with modern power analyzers. However, if tighter loss tolerance uncertainty is needed the accuracy of the measurement instruments should be improved as can be seen in Figure 4 b).

The minimum accuracies for motor measurements are given in [16]. According to [16], the measurement instruments for electrical quantities shall have "the equivalent of an accuracy class of 0.2 in case of a direct test and 0.5 in case of an indirect test in accordance with IEC 60051. The measuring equipment shall reach an overall uncertainty of $0.2 \%$ of reading at power factor 1.0 and shall include all errors of instrument transformers or transducers, if used." For the torque measurement [16] states that "The instrumentation used to measure the torque shall have a minimum class of 0.2. The minimum torque measured shall be at least $10 \%$ of the torque meter's nominal torque. If a better class instrument is used, the allowed torque range can be extended accordingly." For mechanical power measurement, the speed information is naturally required and according to [16], "The speed measurement should be accurate within 0.1 revolution per minute."

Considering how valid is the assumption of evenly distributed measurement uncertainty for input and output power in case of motors (electrical power vs. mechanical power measurement), the total uncertainty value presented in [10] for motors can be used. An advanced measurement uncertainty analysis for $15 \mathrm{~kW}, 37 \mathrm{~kW}$ and $75 \mathrm{~kW}$ induction motors showed total uncertainties of $0.20 \%, 0.21 \%$ and $0.20 \%$ for electrical power measurement and $0.10 \%, 0.12 \%$ and $0.15 \%$ for mechanical power measurement. However, the power analyzer used in [10] is of basic accuracy while the torque transducers are state-of-the-art devices, if a state-of-the-art power analyzer would have been used, the total measurement uncertainty of the active electric power would have been around $0.1 \%$ or even below.

\section{Expected worst-case measurement uncertainty}

The accuracy values given in the standards can be used to derive the expected or worst-case loss uncertainty for the different classes that are used in the electrical machine and converter classifications. 
The calculated worst-case uncertainties are presented in Figure 7 for IE3 motors and IES2 power drive systems with IE2 frequency converters. The requirements for electrical and mechanical measurements are similar for IE and IES classifications but because of much looser requirements for the drive system IES classifications, the uncertainty is much lower for those than for the motors only. Considering the motor efficiency measurement with input-output method according to IEC 60034-2-1, there lies a possibility to an interpretation that can increase the worst-case uncertainty considerably more: The standard states that the minimum measured torque is allowed to be $10 \%$ of the transducer nominal torque and the curve shown in Figure 7 is calculated using 25\% motor torque as the lowest measured torque. The value of the worst-case measurement uncertainty with $25 \%$ torque that is used for all motors when creating Figure $7(0.415 \%$ of torque) is based on analysis presented in [10]. In the mechanical power analysis, speed measurement uncertainty of $0.1 \mathrm{rpm}$ is used and it is assumed to be evenly distributed (rectangular distribution). However, in the input-output method for motors in IEC 60034-2-1, only 100\% motor torque must be measured and if this value is taken as $10 \%$ of the transducer rated torque, the motor loss and PDS loss uncertainty values will be almost $300 \%$ higher. This is a plausible scenario for other motor technologies than induction motors, and for PDSs with all motor technologies including induction motors, as the PDS accuracy requirements for mechanical quantities in [15] are given by referring to IEC 60034-2-1, and only 100\% torque point is required in the IES classification of PDSs. For DOL induction motors, the low uncertainty indirect method must be used, and it is recommended that the additional load losses are determined based on load curve test where $25 \%$ torque is measured. The converter loss uncertainty is calculated here using the power factors of IE3 induction motors with a matching power rating to give more realistic uncertainty value than using the table values from the standard. The power factors are within the limits that are given in the standard.

It can be studied in Figure 7 that using the accuracies given in the corresponding standards, the loss uncertainty of the PDSs is below $5 \%$ for all rated powers. When the input-output method is used for IE3-motors, the loss uncertainty rises from $1 \%$ up to a maximum of $11.2 \%$ with the rated powers above $200 \mathrm{~kW}$. The maximum loss uncertainty of CDMs is $9.2 \%$.

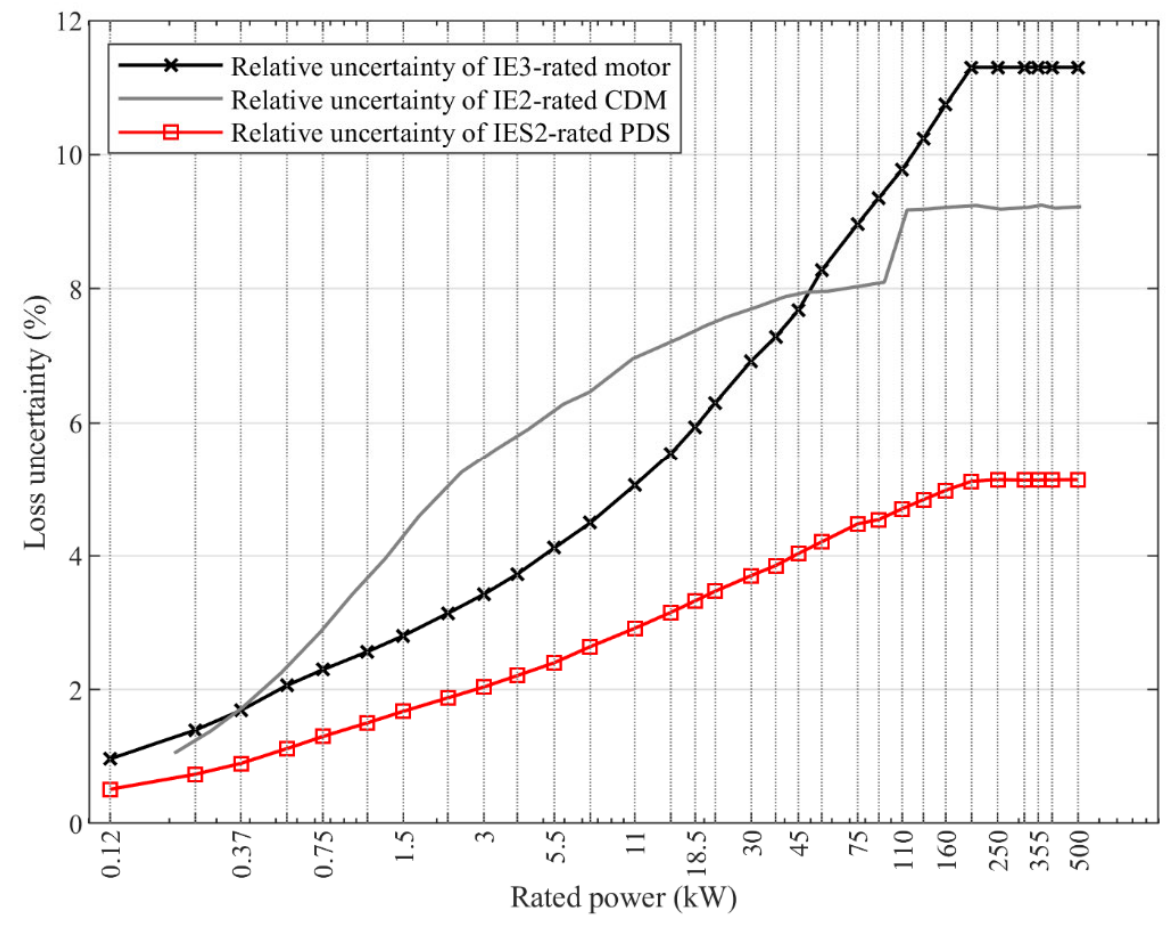

Figure 7. The expected loss uncertainty of IE3-rated motor, IES2-rated PDS and IE2-rated converter as a function of the rated power. 


\section{Discussion}

The reference losses for the frequency converters are remarkably high. A typically used rule-of-thumb -efficiency has been $98 \%$ for two level voltage source converters based on Silicon IGBTs. These kinds of efficiencies have been reported already in the 1990s. This reflects here to the required measurement uncertainty in the converter loss determination, since the measurement uncertainty is examined as a function of the IE-classes. If a realistic converter efficiency or forthcoming IE3-IE5 classes for converters are considered, much lower measurement uncertainty is needed to obtain the $5 \%$ loss tolerance. The standards do not give any methods to control the type A uncertainty in the measurements. Since the averaging of numerous samples and removing minimum and maximum values from the experimental data can be considered to be a generally performed action that is included in the measurement procedure. The type B uncertainty is typically related to the measurement instruments' rated quantity and the relative uncertainty increases when the instrument is used to measure the quantities that are smaller than the rating.

\section{Conclusion}

The most challenging devices from the classification point of view are high-efficiency high-power machines and then the IE2-rated converters. The loss determination uncertainty is a function of the efficiency when the method based on input and output power measurement is used. Both the converter and machine efficiencies rise as a function of the rated power and therefore more accurate measurement methods are required for the devices with higher power ratings if the loss uncertainty is kept at the same level as with the low power devices. The loss determination of the high efficiency devices is challenging, a small error in the input or output power gives substantial rise to loss error. The minimum accuracies of the measurement instruments given in the standards should be reasonable for the given task. The efficiency and loss boundaries that are given in the standards are broad enough and when using the measurement instruments that fulfill the requirements set in the standards, the measurement uncertainty does not play a major role in the efficiency classification. The loss uncertainty of $5 \%$ that is used here is good enough for classification purposes and there is no need to tighten the accuracy demand of the measurement instrument used in the energy efficiency classification of electrical machines and converters.

\section{References}

[1] L. Aarniovuori, J. Kolehmainen, A. Kosonen, M. Niemelä and J. Pyrhönen, "Uncertainty in motor efficiency measurements," 2014 International Conference on Electrical Machines (ICEM), Berlin, 2014, pp. 323-329.

[2] W. Cao,"Comparison of IEEE 112 and New IEC Standard 60034-2-1," IEEE Trans. Energy Conversion, vol. 24, no. 3, pp. 802-808, September 2009.

[3] A. Boglietti, A. Cavagnino and S. Vaschetto, "Induction motor EU standards for efficiency evaluation: The scenario after IEC 60034-2-1," IECON 2011 - 37th Annual Conference of the IEEE Industrial Electronics Society, Melbourne, VIC, 2011, pp. 2786-2791.

[4] G. Bucci, F. Ciancetta, E. Fiorucci and A. Ometto, "Uncertainty Issues in Direct and Indirect Efficiency Determination for Three-Phase Induction Motors: Remarks About the IEC 60034-2-1 Standard," in IEEE Transactions on Instrumentation and Measurement, vol. 65, no. 12, pp. 2701-2716, Dec. 2016.

[5] S. Deda and J. A. de Kock, "Induction motor efficiency test methods: A comparison of standards," 2017 International Conference on the Industrial and Commercial Use of Energy (ICUE), Cape Town, 2017, pp. 16.

[6] B. Deusinger, M. Lehr and A. Binder, "Determination of efficiency of permanent magnet synchronous machines from summation of losses," 2014 International Symposium on Power Electronics, Electrical Drives, Automation and Motion, Ischia, 2014, pp. 619-624.

[7] N. Yogal, C. Lehrmann and M. Henke, "Determination of the Measurement Uncertainty of Direct and Indirect Efficiency Measurement Methods in Permanent Magnet Synchronous Machines," 2018 XIII International Conference on Electrical Machines (ICEM), Alexandroupoli, 2018, pp. 1149-1156. 
[8] L. Aarniovuori, H. Kärkkäinen, A. Kosonen, J. Pyrhönen, Z. Liu and W. Cao, "Overview of calorimetric systems used in loss determination of electric motors and drives," IECON 2017 - 43rd Annual Conference of the IEEE Industrial Electronics Society, Beijing, 2017, pp. 2110-2115.

[9] L. Aarniovuori, T. Musikka, A. Kosonen, M. Niemelä and J. Pyrhönen, "Three alternative methods to determine voltage source converter losses," 2015 17th European Conference on Power Electronics and Applications (EPE'15 ECCE-Europe), Geneva, 2015, pp. 1-10.

[10]H. Kärkkäinen, L. Aarniovuori, M. Niemelä and J. Pyrhönen, "Advanced Uncertainty Calculation Method for Frequency Converter Loss Determination," 2018 20th European Conference on Power Electronics and Applications (EPE'18 ECCE Europe), Riga, 2018, pp. P.1-P.10.

[11]Evaluation of measurement data - Guide to the expression of uncertainty in measurement, Ed. 1, JCGM 100:2008, September 2008, pp. 1-134.

[12] Rotating electrical machines - Part 30-1: Efficiency classes of line operated AC motors (IE code), Ed. 1, IEC 60034-30-1, March 2014.

[13] Rotating electrical machines - Part 1: Rating and performance, Ed. 13.0, IEC 60034-1, May 2017.

[14] Rotating electrical machines - Part 30-2: Efficiency classes of variable speed AC motors (IE-code) Ed. 1, IEC TS 60034-30-2, Dec. 2016.

[15] Adjustable speed electrical power drive systems - Part 9-2: Ecodesign for power drive systems, motor starters, power electronics and their driven application - Energy efficiency indicators for power drive systems and motor starters, Ed. 1, IEC 61800-9-2, March 2017.

[16] Rotating electrical machines - Part 2-1: Standard methods for determining losses and efficiency from tests (excluding machines for traction vehicles), Ed. 2, IEC 60034-2-1, June 2014. 